\title{
A Defected Ground Structure without Ground Contact Problem and Application to Branch Line Couplers
}

\author{
Jongsik Lim, ${ }^{1}$ Dal Ahn, ${ }^{1}$ Sang-Min Han, ${ }^{1}$ Yongchae Jeong, ${ }^{2}$ and Haiwen Liu ${ }^{3}$ \\ ${ }^{1}$ Soonchunhyang University, Asan, Chungnam 336-745, Republic of Korea \\ ${ }^{2}$ Chonbuk National University, Jeonju, Chonbuk 561-756, Republic of Korea \\ ${ }^{3}$ East China of Jiaotong University, Nanchang 330013, China \\ Correspondence should be addressed to Jongsik Lim; jslim@sch.ac.kr
}

Received 26 March 2013; Revised 11 June 2013; Accepted 23 June 2013

Academic Editor: Sha Luo

Copyright (C) 2013 Jongsik Lim et al. This is an open access article distributed under the Creative Commons Attribution License, which permits unrestricted use, distribution, and reproduction in any medium, provided the original work is properly cited.

\begin{abstract}
A new defected ground structure (DGS) microstrip line that is free from the ground contact problem is described together with its application example. The proposed DGS microstrip line adopts a double-layered substrate. The first layer contains the microstrip line and DGS patterns on the top and bottom planes as with the conventional DGS line. The second substrate, of which upper metal plane has already been removed, is attached to the bottom ground plane of the first layer. This structure prevents the ground plane of the first substrate with DGS patterns from making contact with the metal housing. The proposed DGS microstrip line has advantageous transmission and rejection characteristics, without the ground contact problem of DGS patterns, which has been a critical problem of previous DGS lines. A $10 \mathrm{~dB}$ branch line hybrid coupler is designed and measured, as an example of application of the proposed DGS microstrip line.
\end{abstract}

\section{Introduction}

Normal microstrip lines theoretically have all pass characteristics. However, it has been extensively known that if perforating patterns, such as photonic bandgap (PBG) and defected ground structure (DGS), are inserted on the ground plane, the transmission characteristics change severely from those of normal transmission lines $[1,2]$.

The advantages of DGS described in previous studies are the as follows. (1) It is easily performed to extract the equivalent circuit model [3], (2) it is well applied to $\mathrm{RF} /$ microwave circuits to reduce sizes or improve performances [4], and (3) DGS raises the realizable upper limit of the characteristic impedance of a microstrip line to around $200 \Omega$ [5-7]. According to previous works, $150 \Omega, 158 \Omega$, and $207 \Omega$ microstrip lines have been realized due to DGS and used in unequal power dividers and couplers. It should be noted that the realizable limit of characteristic impedance of normal microstrip lines is around $110 \Omega \sim 120 \Omega$ [8].

However, in the previous microstrip lines with DGS, hereinafter "DGS microstrip line" or "DGS line," there has been a serious problem when they are packaged in metallic housing because the bottom ground plane of microstrip lines, where DGS patterns are realized, makes direct contact with the metallic package. Then, it is definite that the advantageous effects of DGS are removed, when the inner bottom of the housing and the lower plane of microstrip lines make contact with each other.

In this work, the DGS line that adopts a double-layered substrate structure is described, in order to solve the ground contact problem of DGS lines. In the proposed structure, DGS patterns are realized on the ground plane of microstrip lines as in previous cases. However, the second substrate, of which dielectric material is exposed to the top plane, is attached to the ground plane of the first substrate, where the DGS patterns exist. Therefore, it is possible to remove the ground contact problem of DGS, while the advantages of DGS are preserved. As an example of application, a $10 \mathrm{~dB}$ branch line hybrid coupler is designed and measured.

\section{DGS Lines Using Double-Layered Substrate}

Figure 1 shows the existing DGS microstrip line. Even though it has advantages over normal microstrip lines, it has also 


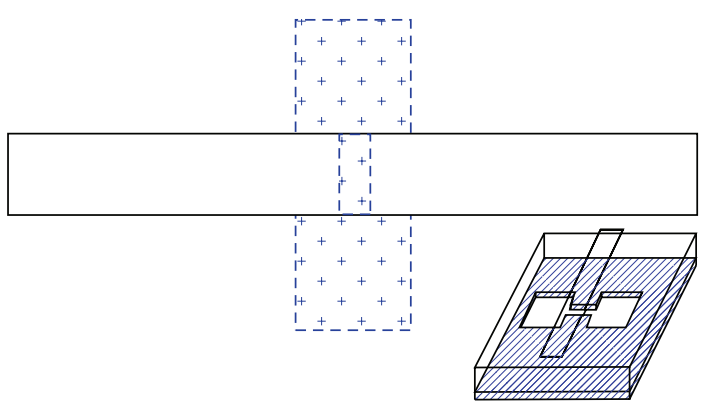

FIGURE 1: Microstrip line having DGS on the ground plane.

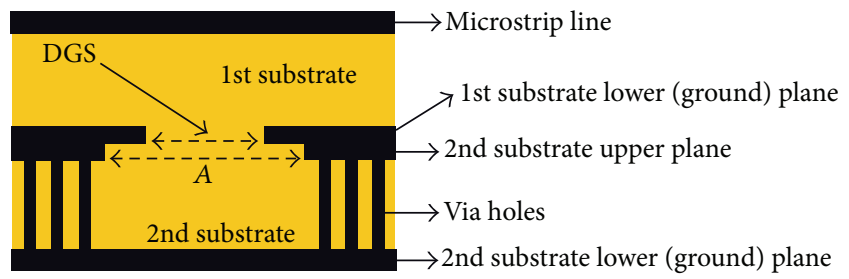

Figure 2: DGS line using the double-layered substrate. Area " $A$ " completely contains the DGS patterns.

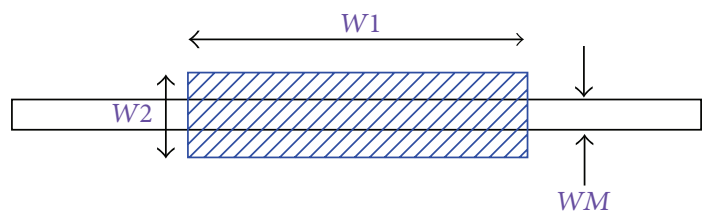

Figure 3: Microstrip line having double-layered substrate and rectangular DGS.

the critical problem that it cannot be inserted into a metal housing. If the bottom ground plane is directly faced with a metal box, the main characteristics of DGS immediately disappear because the etched DGS patterns are compensated for by the metallic bottom surface of the housing, so it becomes a new normal microstrip line. Therefore, the DGS plane should be separated from the metallic package for the advantages of DGS to be preserved.

Figure 2 shows the DGS microstrip line with a doublelayered substrate in this work. It is easily understood that the structure in Figure 2 prevents the DGS patterns from directly contacting the surface of the metallic housing. In the conventional DGS lines, DGS patterns are realized on the ground plane of the first substrate. However in this work, the second substrate is attached to the first substrate, so that the DGS cannot directly face the metal housing. Basically, the whole upper metal plane of the second substrate might be removed. However; the specific area designated as " $A$ " in Figure 2 may be selectively erased. It is important that area " $A$ " should completely contain the DGS patterns.

It is important that the bottom planes of the first and second substrates should be connected through lots of viaholes for the same ground potential. Although it is preferred that the thickness of the second substrate should be as thin as possible, this is not critical because the top and bottom metal planes of the second substrate are connected by a lot of via

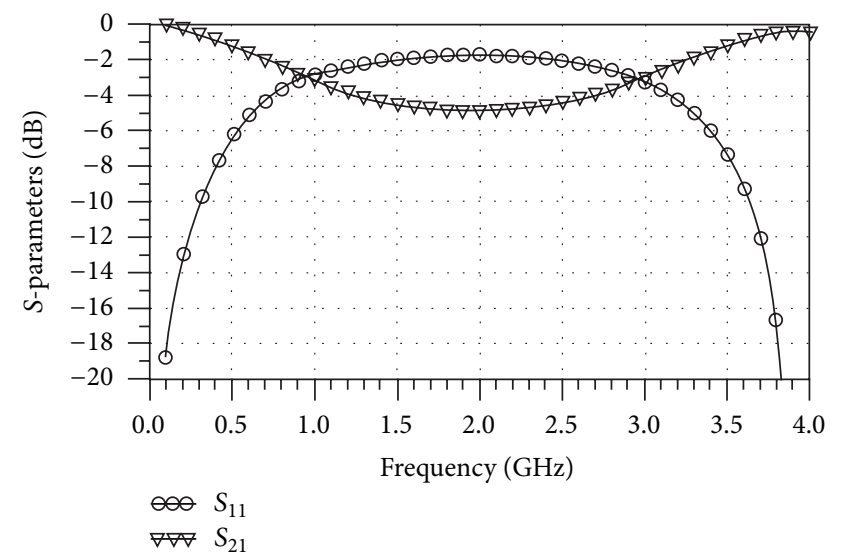

FIGURE 4: Electromagnetically calculated $S$-parameter of the DGS line shown in Figure $3(W 1=20 \mathrm{~mm}, W 2=5 \mathrm{~mm}, W M=0.20 \mathrm{~mm})$.

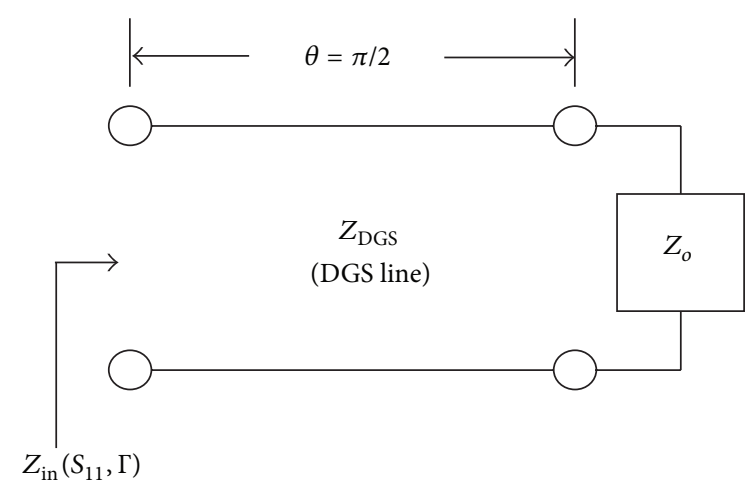

FIGURE 5: Equivalent circuit model to determine the characteristic impedance of the DGS line.

holes for the same ground potential. It is easily understood that the ground plane of the second substrate makes contact with the inner bottom of the metallic housing.

\section{Characteristic Impedance Analysis}

Figure 3 shows the top view of the adopted DGS line in this work, which consists of a microstrip line and rectangularshaped DGS on the bottom ground plane of the first substrate. The second substrate is not shown here, even though it is attached to the first substrate. "W1" and "W2" are 


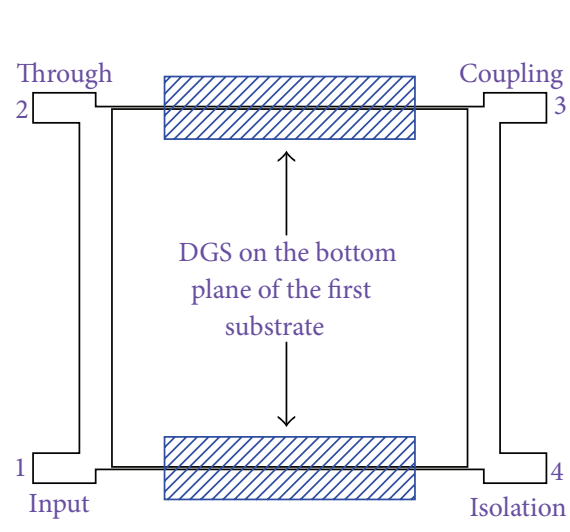

(a)

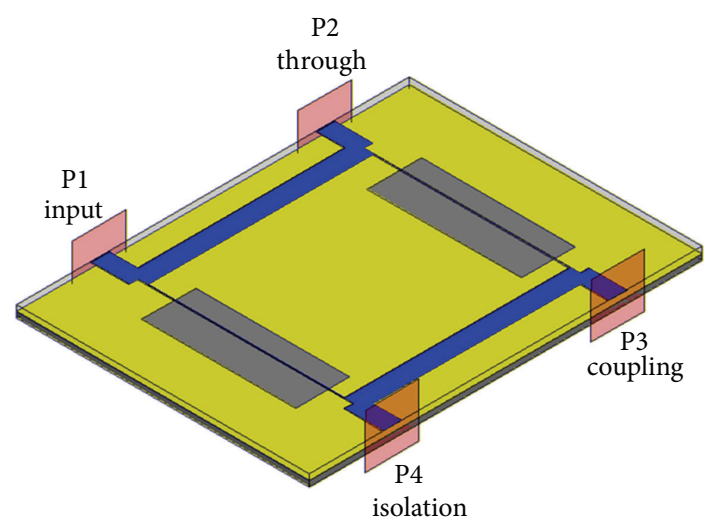

(b)

FIGURE 6: Layout of the proposed $10 \mathrm{~dB}$ hybrid coupler using DGS and double-layered substrate: (a) 2-dimensional view and (b) 3-dimensional view.

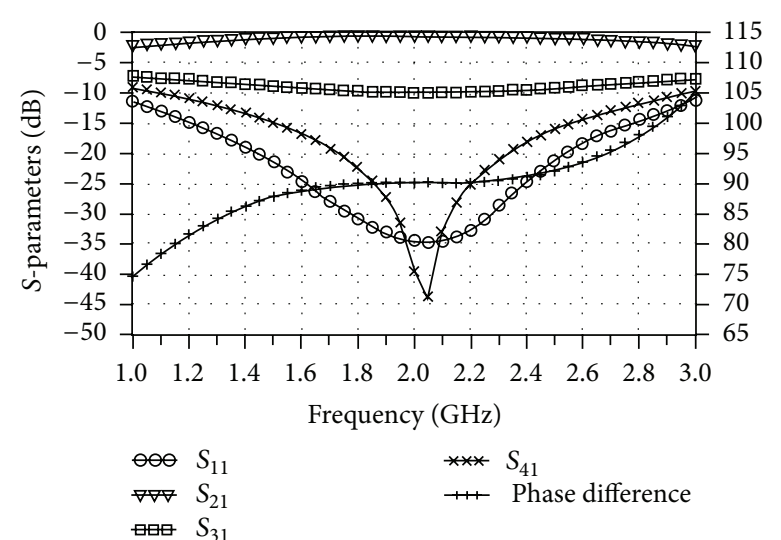

FIGURE 7: Simulated performances of the $10 \mathrm{~dB}$ branch line hybrid coupler.

the dimensions of the rectangular DGS, and "WM" is the width of the microstrip line on the top plane of the first substrate. The dielectric constant $\left(\varepsilon_{r}\right)$ and thickness of the first substrate in this work are 2.2 and 31 mils, respectively. The same substrate has been selected as the second substrate, for convenience.

When the rectangular-shaped DGS is realized on the ground plane of the first substrate, the effectively added inductance highly increases, as has already been discussed in many previous works, while the added effective capacitance is relatively small. As the result, a microstrip line is obtained with higher characteristic impedance than the normal one for the same line width.

Figure 4 illustrates the electromagnetically simulated $S$ parameter of the DGS line shown in Figure 3. The $S_{11}$ is around $-1.9 \mathrm{~dB}$, which corresponds to $150 \Omega$ line impedance.

Figure 5 and (1)-(3) are useful for calculating the characteristic impedance of the DGS line. Figure 5 shows the transmission line model of the DGS line to determine the characteristic impedance $\left(Z_{\mathrm{DGS}}\right)$. When $\theta=\pi / 2$ at the center frequency, the magnitude of the reflection coefficient $(|\Gamma|)$ is maximum, so it can be calculated from $S_{11}$ by (1). Once $|\Gamma|$ is known, $Z_{\text {in }}$ is calculated by (2). Finally, $Z_{\mathrm{DGS}}$ is calculated from (3):

$$
\begin{gathered}
S_{11}[\mathrm{~dB}]=20 \log |\Gamma|, \\
Z_{\text {in }}=Z_{0} \frac{1+|\Gamma|}{1-|\Gamma|} \\
Z_{\mathrm{DGS}}=\sqrt{Z_{\text {in }} Z_{0}}=Z_{0} \sqrt{\frac{1+|\Gamma|}{1-|\Gamma|}} .
\end{gathered}
$$

\section{Application to Branch Line Hybrid Couplers}

A $10 \mathrm{~dB}$ branch line hybrid coupler having a conventional 1-layered DGS has already been proposed in [7]. Quarterwave microstrip lines with $150 \Omega$ and $47.4 \Omega$ of characteristic impedances should be provided to design $10 \mathrm{~dB}$ hybrid couplers. It is very difficult to realize $150 \Omega$ of microstrip line using a reasonable aspect ratio of the conventional microstrip line. Furthermore, a serious ground problem exists in the previous $150 \Omega$ DGS line.

Figure 6 shows the 2- and 3-dimensional views of the designed $10 \mathrm{~dB}$ hybrid coupler using the proposed DGS line structure. The rectangular DGS shown in Figure 3 is used for the $150 \Omega$ line.

Figure 7 illustrates the simulated $S$-parameters of the $10 \mathrm{~dB}$ hybrid coupler. Electromagnetic (EM) simulations have been performed on Ansoft HFSS and Agilent ADS Momentum, and these two simulators produced the similar results. The predicted $S_{21}$ and $S_{31}$ at the center frequency are $-0.6 \mathrm{~dB}$ and $-10.3 \mathrm{~dB}$, respectively.

Figure 8 shows circuit layouts of the fabricated $10 \mathrm{~dB}$ hybrid coupler. DGS patterns are directly contacted with the broadly exposed area (" $A$ ") of the second substrate. In Figure $8(\mathrm{~b})$, the other metal area remains, except " $A$ " in the upper plane of the second substrate, as has been illustrated in Figure 2. The dimensions of the rectangular-shaped DGS and exposed area " $A$ " are " $20 \mathrm{~mm} \times 5 \mathrm{~mm}$ " and " $26 \mathrm{~mm} \times 10 \mathrm{~mm}$," respectively. 


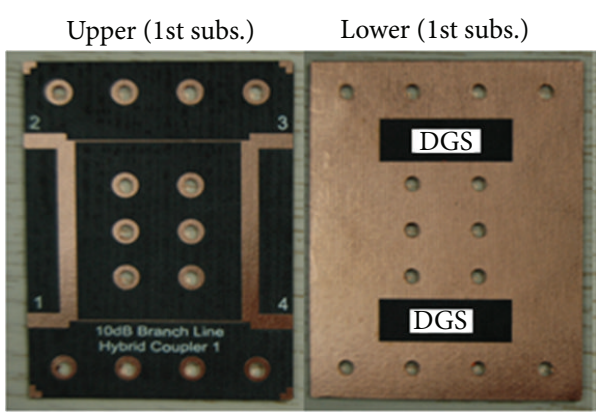

(a)

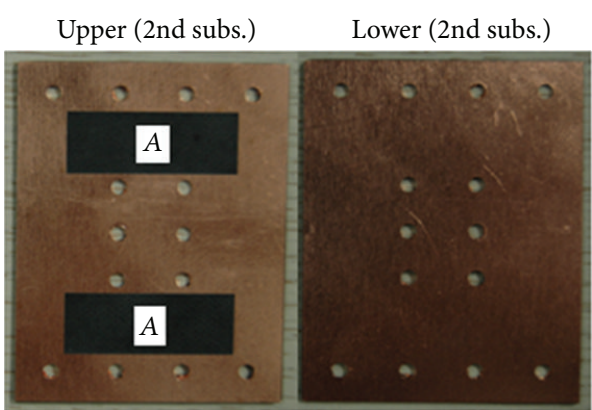

(b)

FIgURE 8: Photographs of the fabricated substrates of $10 \mathrm{~dB}$ hybrid coupler (a) first substrate and (b) second substrate.

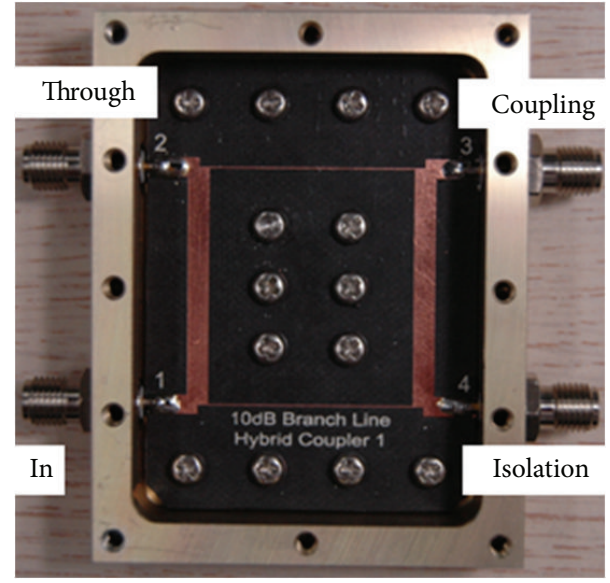

Figure 9: Fabricated $10 \mathrm{~dB}$ hybrid coupler inserted into a metal housing.

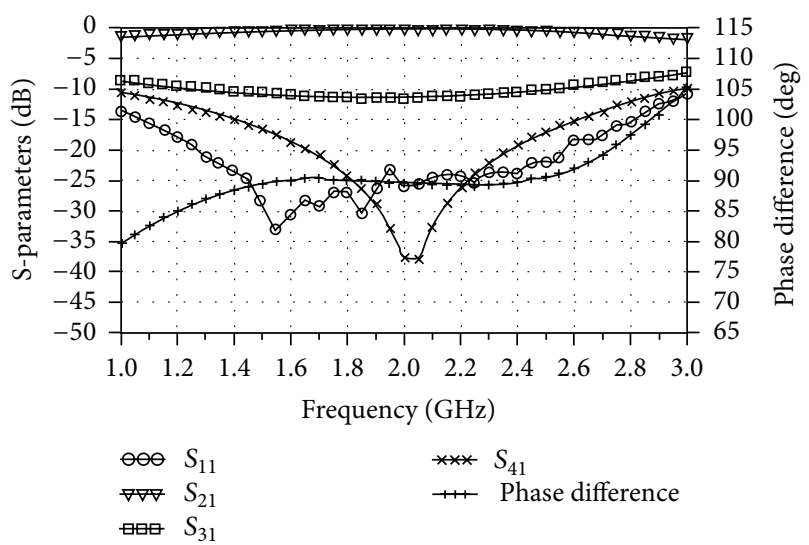

Figure 10: Measured $S$-parameters of the fabricated $10 \mathrm{~dB}$ branch line hybrid coupler.

Figure 9 shows the fabricated $10 \mathrm{~dB}$ hybrid coupler inserted in a metallic housing. In packaging the $10 \mathrm{~dB}$ coupler into the housing, no ground contact problem of DGS occurs, unlike the conventional DGS cases with single layer.

Figure 10 shows the measured $S$-parameters of the fabricated $10 \mathrm{~dB}$ hybrid coupler. Even though some minor discrepancies are observed, the measured performances show an excellent agreement with the predicted ones in matching, inserting loss, and isolation characteristics. The measured $S_{21}$ and $S_{31}$ at center frequency are $-0.45 \mathrm{~dB}$ and $-11.5 \mathrm{~dB}$, respectively, which well prove the performances of the $10 \mathrm{~dB}$ coupler.

\section{Conclusions}

In this work, a DGS line adopting a double-layered substrate has been described that has no ground contact problem in metallic packages. The DGS patterns have been separated from the metallic housing, by adding a second substrate to the conventional 1-layered DGS plane. As an application example, a $150 \Omega$ DGS line has been designed and applied to a $10 \mathrm{~dB}$ branch line hybrid coupler. The measured performances were in excellent agreement with the predicted ones.

It has been shown that the proposed DGS line with double-layered substrate solved the ground contact problem of the conventional DGS line, while the advantages of DGS are preserved. Unlike the previous works, the realized $10 \mathrm{~dB}$ hybrid coupler in this work has been inserted into a metallic package and successfully measured. It is expected that the proposed method can be applied to other RF/microwave circuits that have perforated ground patterns, such as DGS and PBG.

\section{References}

[1] V. Radisic, Y. Qian, R. Coccioli, and T. Itoh, "Novel 2-D photonic bandgap structure for microstrip lines," IEEE Microwave and Guided Wave Letters, vol. 8, no. 2, pp. 69-71, 1998.

[2] C.-S. Kim, J.-S. Park, D. Ahn, and J.-B. Lim, "A novel 1-D periodic defected ground structure for planar circuits," IEEE Microwave and Wireless Components Letters, vol. 10, no. 4, pp. 131-133, 2000.

[3] D. Ahn, J.-S. Park, C.-S. Kim, J. Kim, Y. Qian, and T. Itoh, "A design of the low-pass filter using the novel microstrip defected ground structure," IEEE Transactions on Microwave Theory and Techniques, vol. 49, no. 1, pp. 86-93, 2001.

[4] J.-S. Lim, J.-S. Park, Y.-T. Lee, D. Ahn, and S. Nam, "Application of defected ground structure in reducing the size of amplifiers," IEEE Microwave and Wireless Components Letters, vol. 12, no. 7, pp. 261-263, 2002. 
[5] J.-S. Lim, S.-W. Lee, C.-S. Kim, J.-S. Park, D. Ahn, and S. Nam, "A 4:1 unequal Wilkinson power divider," IEEE Microwave and Wireless Components Letters, vol. 11, no. 3, pp. 124-126, 2001.

[6] J.-S. Lim, G.-Y. Lee, Y.-C. Jeong, D. Ahn, and K.-S. Choi, "A 1:6 unequal wilkinson power divider," in Proceedings of the 36th European Microwave Conference (EuMC '06), pp. 200-203, September 2006.

[7] J.-S. Lim, C.-S. Kim, J.-S. Park, D. Ahn, and S. Nam, "Design of $10 \mathrm{~dB} 90^{\circ}$ branch line coupler using microstrip line with defected ground structure," Electronics Letters, vol. 36, no. 21, pp. 1784-1785, 2000.

[8] K. C. Gupta, Microstrip Lines and Slotlines, Artech House, Norwood, Mass, USA, 1996. 

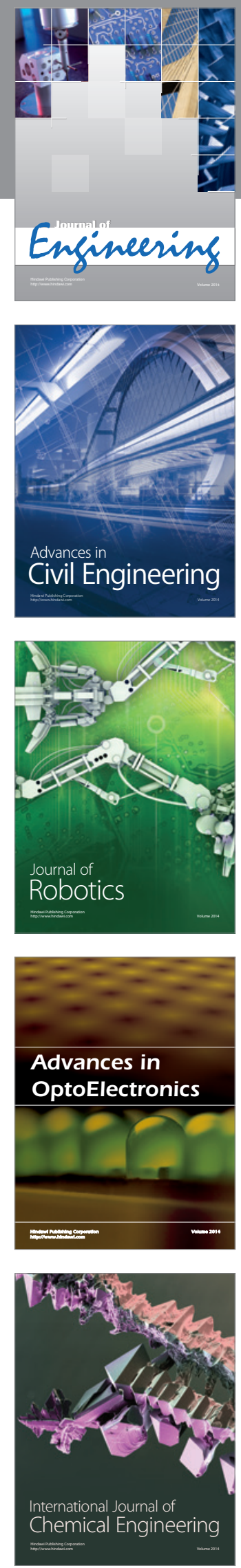

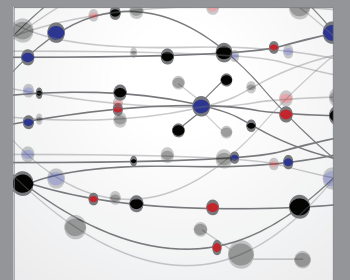

The Scientific World Journal
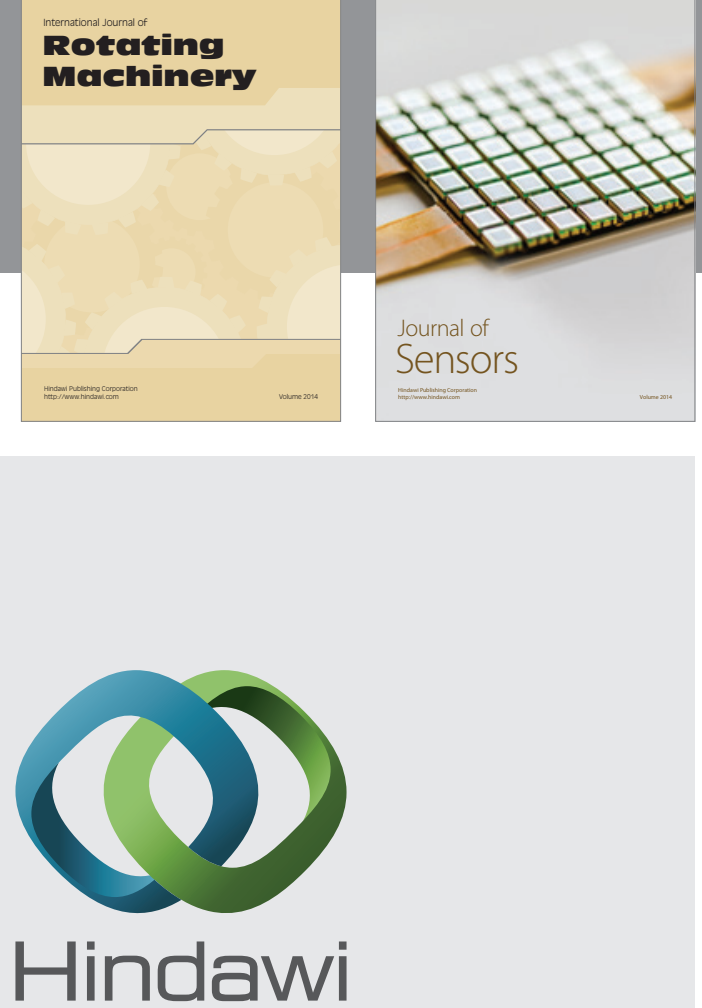

Submit your manuscripts at http://www.hindawi.com
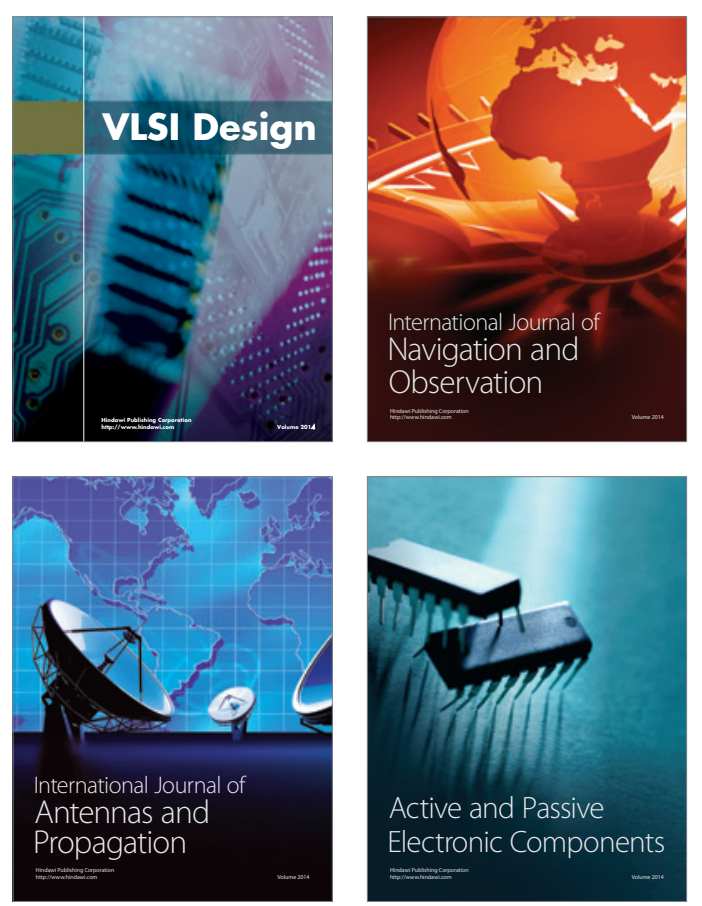
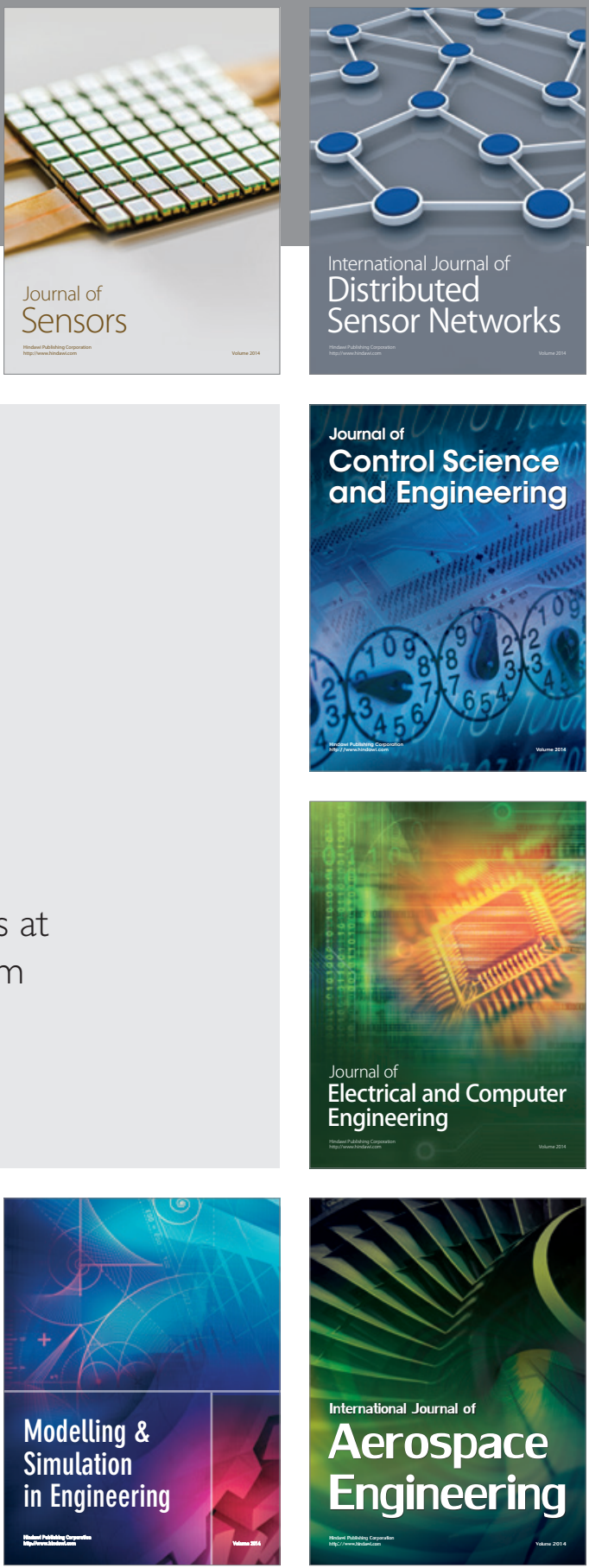

Journal of

Control Science

and Engineering
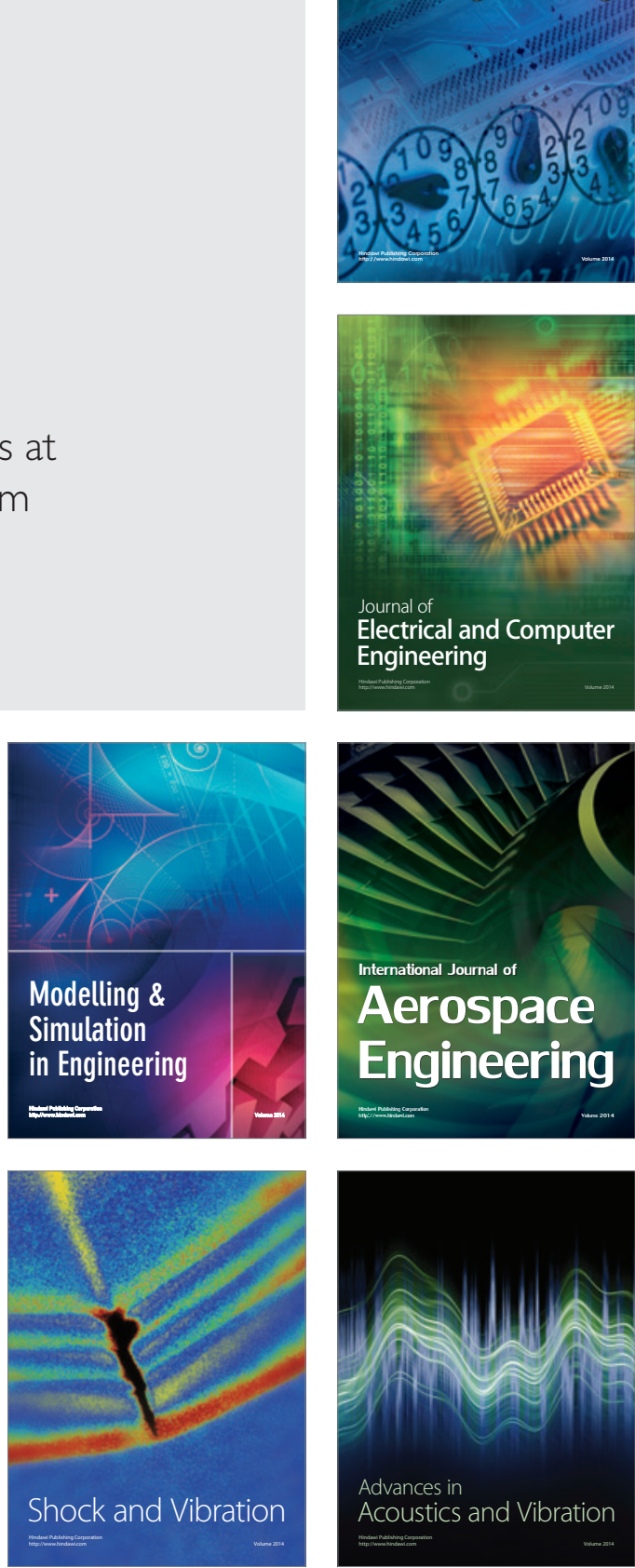